\title{
Giant Left Atrium: A Cause of Atrial Fibrillation and Rare Entity in Chronic Rheumatic Valvular Heart Disease: A Case Report
}

\author{
Aditi Pandey ${ }^{1}$, Aniket Kumar ${ }^{2}$ \\ ${ }^{1,2}$ MD Medicine, Department of Medicine, Rajendra Institute of Medical Sciences, Ranchi
}

\begin{abstract}
A 35 year old male with known rheumatic heart disease presented to the emergency department with progressively increasing breathlessness.Two dimensional echocardiography followed by CECT chest revealed giant left atrium $(17.7 \mathrm{cmx16.1 \textrm {cm } ) . T h e ~ l a r g e s t ~ l e f t}$ atrium described so far in literature is $18.7 \mathrm{~cm}$,reported by Mehmet et al and from India is $18.4 \mathrm{~cm} x 11 \mathrm{~cm} x 10.2 \mathrm{~cm}$.So this is third largest in world and second largest in India.
\end{abstract}

Keywords: Giant left atrium, mitral stenosis, atrial fibrillation, mitral regurgitation, rheumatic heart disease

\section{Introduction}

Left atrial enlargement is a common feature of rheumatic valvular disease.Other causes are left ventricular failure,chronic atrial fibrillation,significant left to right shunts,patent ductusarteriosus, ventricular septal defect.Giant left atrium is uncommonly seen in mitral stenosis. We here report a case of rheumatic mitral stenosis with mild mitral regurgitation present with one of the largest left atrium described so far.

\section{Case Report}

A 35 yearold male presented with symptoms of breathlessness, fatigue and intermittent palpitation for the last 2 yrs.that worsened in the last 1 month.The patient was under treatment with combination of frusemide and spironolactone.On examination, heart rate was 106/minute,irregularly irregular and blood pressure was 94/60 mm of Hg.On cardiacexamination, apex beat was localised to $6^{\text {th }}$ intercostal space lateral to mid-clavicular line. On auscultation, thefirst heart sound was variable, the second heart sound was narrowly split with loud P2.There was a rough rumbling mid-diastolic murmur and a

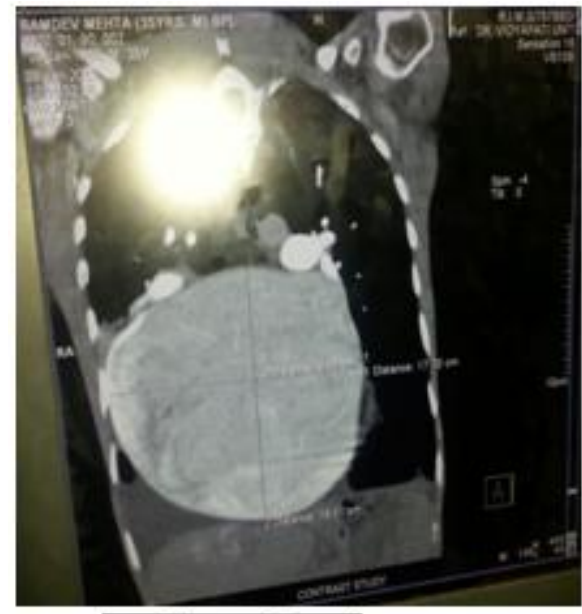

Figure 1

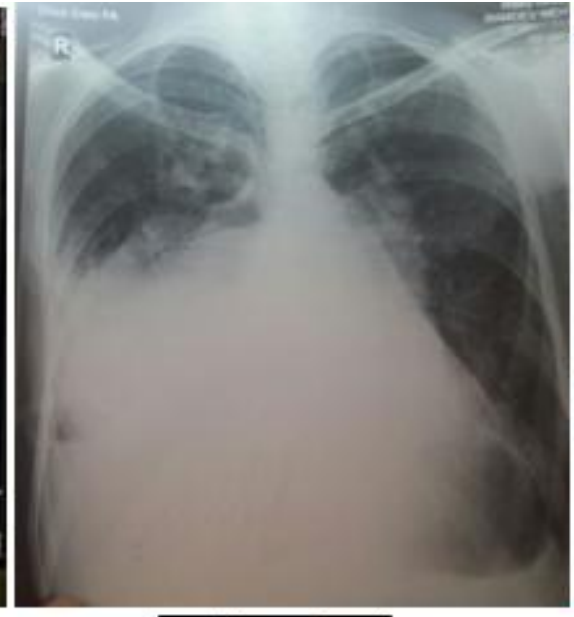

Figure 2

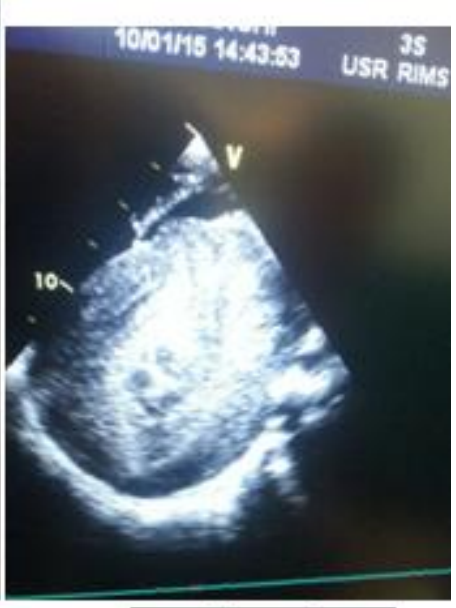

Figure 3 pansystolic murmur best heard at the apex radiating to the left axilla.His routine examination was normal.A chest x-ray (fig. 2) revealed gross enlargement of cardiac silhouette.Trans-thoracic echocardiography (fig. 3) showed a massively dilated left atrium, which was further confirmed by CECT chest(fig. 1) that revealed the size of left atrium $17.7 \mathrm{~cm} \times 16.1 \mathrm{~cm}$, mitral valve area- $0.7 \mathrm{~cm}^{2}$ and there was colourdoppler evidence of mild mitral regurgitation,mild tricuspid regurgitation withmoderate pulmonary arterial hypertension.
In view of clinical examination and $2 \mathrm{D}$ echo the patient was diagnosed as a case of rheumatic heart disease with severe mitral stenosis with mild mitral regurgitationand mild tricuspid regurgitation with atrial fibrillation and giant left atrium.Despite having giant left atrium,the patient did not have compressive symptoms like dysphagia or hoarseness of voice. 


\section{International Journal of Science and Research (IJSR) \\ ISSN (Online): 2319-7064}

Index Copernicus Value (2015): 78.96 | Impact Factor (2015): 6.391

\section{Discussion}

According to Ismura and co-workers, giant left atrium means left atrium greater than $6 \mathrm{~cm}$.Hurst states that in case of giant left atrium, mitral regurgitation is more common than mitral stenosis and atrial fibrillation is almost always present.Till date, the largest left atrium is $18.7 \mathrm{~cm}$,reported by Mehmet et al.In our case $\mathrm{x}$ ray shows enlarged cardiac silhouette.On two dimensional echocardiography, it was confirmed as giant left atrium and then CECT revealed the size $17.7 \mathrm{~cm} \times 16.1 \mathrm{~cm}$.Giant left atrium rarely presents with severe mitral stenosis, but in our case it was associated with severe mitral stenosis with mild mitral regurgitation and mild tricuspid regurgitation with atrial fibrillation.The patientof giant left atrium presents usually with complain of shortness of breath and dysphagia.Our patienthad mild chest pain,shortness of breath on exertion without compressive symptoms and had no evidence of acute rheumatic carditis or bacterial endocarditis during the course of illness.Such giant left atriumwith severe mitral stenosis with mild mitral regurgitation is a rare entity.So we report it.

\section{References}

[1] Isomura $\mathrm{T}$, Hisatomi $\mathrm{K}$, Hirano A, Maruyama $\mathrm{H}$, Kosuga K, Ohishi K. Left atrial plication and mitral valve replacement for giant left atrium accompanying mitral lesion. J Card Surg 1993;8:365-70. [PubMed]

[2] Sinatra R, Pulitani I, Antonazzo A, Melina G. A novel technique for giant left atrium reduction. Eur J CardiothoracSurg 2001;20:412-4. [PubMed]

[3] Hurst JW. Memories of patients with a giant left atrium. Circulation 2001;104:2630-1. [PubMed]

[4] M, Sensoz Y, Abay G, Akcar M: Giant left atrium with rheumatic mitral stenosis. Tex Heart Inst J 2006, 33(3):389-391.

[5] Farman MT, Sial JA, Khan N, Rahu QA, Tasneem H, Ishaq $\mathrm{H}$ : Severe mitral stenosis with atrial fibrillation-a harbinger of thromboembolism. J Pak Med Assoc 2010, 60(6):439-43.

[6] Funk M, Perez M, Santana O: Asymptomatic giant left atrium. ClinCardiol 2010, 33: E104-E105. 10.1002/clc. 20736 